\title{
Recurrence Risk of Febrile Seizures in Children
}

\author{
Ojha AR', Shakya KN ${ }^{1}$, Aryal UR ${ }^{2}$
}

${ }^{1}$ Dr. Anil Raj Ojha, MBBS, MD, Lecturer, Department of Paediatrics, ${ }^{2}$ Dr. KN Shakya, MBBS, FCPS, Department of Paediatrics, ${ }^{3}$ Dr. UR Aryal, MSc (Statistics), Department of Community Medicine. All from Kathmandu Medical College and Teaching Hospital, Sinamangal, Kathmandu, Nepal.

\begin{abstract}
Introduction: Febrile seizure is a common paediatric problem. Identifying children with febrile seizure who are at risk for recurrence is important so that special attention can be given to them. The objective of this study was to identify the risk factors for recurrence of febrile seizures in children. Materials and Methods: This was a prospective cohort study done at Kathmandu Medical College and Teaching Hospital, Kathmandu, Nepal. This study is a continuation of a previous study which looked at the leucocytosis in peripheral blood of children with febrile seizure. A detailed history including the risk factors for febrile seizure recurrence was obtained from the caregiver during follow up on subsequent days after discharge of children from the hospital who were previously admitted for febrile seizure. All children with febrile seizure belonging to age group of 6 months to 6 years were included in the study. Those with afebrile seizures or on anticonvulsants and those who refused to give consent were excluded. Each child was also examined and investigated for the cause of fever. Results: A total of 115 children with febrile seizure admitted for febrile seizure during the study period and all of them were followed up at outpatient department. Males accounted $62 \%$ and females $38 \%$. Simple Febrile Seizures were seen in $80 \%$ of the cases and complex febrile seizures were seen in $20 \%$. Out of all the cases $68(59 \%)$ had symptoms of viral prodrome. 59(51\%) had recurrent febrile seizure. Low temperature at onset of Febrile Seizure $(p=0.001)$, short duration of fever before onset of Febrile Seizure $(0.026)$ and atypical Febrile Seizure $(p=0.022)$ were the risk factors for recurrent febrile seizure. Conclusion: Febrile Seizure is a common paediatric problem commonly seen in males. Almost half of children with Febrile Seizure are at risk for recurrence in later date. The risk factors for these recurrences are modest rise in body temperature at the onset of febrile seizure, onset of seizure within 12 hours of fever and atypical presentation.
\end{abstract}

Key words: Epilepsy, Febrile Seizure, Typical Febrile Seizure, Recurrence

\section{Introduction}

Eebrile seizure is a seizure which occurs in presence of a clinically recognizable infection with exclusion of central nervous system infection'.

Febrile Feizure (FS) is a common childhood problem ${ }^{2}$. It is of two types namely simple and complex febrile seizure. Simple febrile seizures are generalized seizures, lasting less than 15 minutes, not recurring within 24 hours, and with no postictal neuro-logical abnormalities. Complex febrile seizures are focal, prolonged or recurrent within 24 hours or associated with post-ictal neurological abnormalities including Todd paresis ${ }^{3}$.

Febrile seizure can recur. Pavlidou $\mathrm{E}^{4}$ et al in their study found $48 \%$ had recurrence of febrile seizure. There are controversial data on risk factors for recurrences and there are debates putting a child on anticonvulsant prophylaxis having recurrences. In this context this study can be a useful to know about the risk factors involved in recurrence of febrile seizure.

This can guide a physician for possible intervention such as putting the child on prophylaxis treatment for seizures. This is important because attack of febrile seizure is a traumatic experience both for the child and the parents. The aim of this study was to identify the risk factors for recurrent febrile seizure

\section{Materials and Methods}

This is a prospective cohort study done at Kathmandu Medical College and Teaching Hospital, Sinamangal, Kathmandu, Nepal. It is the continuation of the study which looked for the leucocytosis in peripheral blood in children with febrile seizure ${ }^{5}$. These children 
were followed at outpatient department of Paediatrics at Kathmandu Medical College and the study was conducted from July 2008 to July 2009.

All the children who were admitted previously for febrile seizure were asked to follow up within a week of discharge. Children belonging to age 6 months to 6 years were included in the study. Informed consent was taken. Children younger than 6 months and older than 6 years of age, those who had afebrile seizures, those who are on regular anticonvulsants treatment and those who refused to give consent were excluded from the study.

The parents of children were interviewed during the follow up on outpatient department by asking screening questions to verify that the child had not had afebrile seizures. A complete description of the seizure from the parent or, from an eyewitness was taken. Information were asked for about; prenatal and perinatal history of each child, family history of febrile seizure and epilepsy, age during first febrile convulsion (in cases of $\geq 1$ recurrences), presence or absence of focal features, duration of the febrile seizure, the duration of fever prior to the seizure and whether repeated episodes within the same febrile illness had occurred or not. Complete physical, developmental and neurologic assessments were conducted in each child. On arrival temperature was taken and the child was investigated for fever as per the decision of treating physician.

Simple febrile seizures are pre-defined as generalized seizures, lasting less than $15 \mathrm{~min}$, not recurring within 24 hours, and with no postictal neurological abnormalities. Similarly complex febrile seizures are focal, prolonged or recurrent within 24 hours or associated with post-ictal neurological abnormalities including Todd paresis ${ }^{3}$.

Those children who had had a past history of at least one febrile seizure and presently coming with another episode of febrile seizure were regarded as recurrent febrile seizure.
The collected data were entered in excel and analyzed using SPSS 11.5. The results were analyzed by descriptive statistics and Chi square test.

\section{Results}

During the study period caretakers of 115 children who were previously admitted for febrile seizure, were interviewed. Males accounted for $62 \%$ and females $38 \%$. Simple febrile seizure were seen in $93(80 \%)$ and complex febrile seizure in $22(20 \%)$. In the study group, $16(14 \%)$ had family history of FS and $11(10 \%)$ had family history of seizure disorder. There were two patients who had psychomotor retardation and one case had history of birth asphyxia.

Among the causes of fever in the study, 68(59\%) had symptoms of viral prodrome, $17(15 \%)$ had non-specific febrile illness, 10(9\%) had UTI. Acute pharyngotonsillitis, otitis media, dysentery and pneumonia accounted for $5(4 \%)$ of total causes of fever. Bacteremia was seen in two children. One child had Staphylococcus aureus while Salmonella species was isolated in another. There were $10(9 \%)$ cases of culture proven UTI. Lumbar puncture was done in seven $(6 \%)$ but none had meningitis or encephalitis.

Recurrent febrile seizure was found in 59(51\%) children and the rest 56 (49\%) had febrile seizure for the first time.

As seen in Table 1 there was a statistical association between low temperature at onset of seizure and recurrences of febrile seizures $(p<0.001)$. Similarly, the association of duration of fever ( $\leq 12$ hour) prior to onset of febrile seizure and recurrence was found to be significant $(p=0.026)$. Moreover it was found that complex febrile seizure had a statistically significant association with its recurrence $(p=0.022)$.

Age of the child at the onset of first febrile seizure, sex and family history of epilepsy were not found to be significantly associated risk factors for the recurrence of febrile seizure. 
Table 1: Factors associated with FS recurrence

\begin{tabular}{|c|c|c|c|c|c|}
\hline Risk factors & Variables & $\begin{array}{l}\text { Number of children } \\
\qquad(\mathrm{N}=115)\end{array}$ & $\begin{array}{c}\text { Number of } \\
\text { children without } \\
\text { recurrence }(\mathrm{N}=56)\end{array}$ & $\begin{array}{c}\text { Number of children } \\
\text { with recurrence } \\
(\mathrm{N}=59)\end{array}$ & $p$-value \\
\hline \multirow{2}{*}{ Age } & $\leq 18$ months & 45 & 18 & $27(60)$ & \multirow{2}{*}{0.135} \\
\hline & $>18$ months & 70 & 38 & $32(46)$ & \\
\hline \multirow{2}{*}{ Sex } & Boys & 71 & 36 & $35(50)$ & \multirow{2}{*}{0.584} \\
\hline & Girls & 44 & 20 & $24(54)$ & \\
\hline \multirow{2}{*}{ Family history of FS } & Positive & 16 & 5 & $11(69)$ & \multirow{2}{*}{0.132} \\
\hline & Negative & 99 & 51 & $48(48)$ & \\
\hline \multirow{2}{*}{$\begin{array}{l}\text { Family history of } \\
\text { epilepsy }\end{array}$} & Positive & 11 & 5 & $6(54)$ & \multirow{2}{*}{0.821} \\
\hline & Negative & 104 & 51 & $53(51)$ & \\
\hline \multirow{2}{*}{ Temperature } & $\leq 100 \mathrm{~F}$ & 52 & 12 & $40(77)$ & \multirow{2}{*}{$<0.001$} \\
\hline & $>100 \mathrm{~F}$ & 63 & 44 & 19(30) & \\
\hline \multirow{2}{*}{ Type of FS } & Simple & 93 & 50 & $43(46)$ & \multirow{2}{*}{0.022} \\
\hline & Complex & 22 & 6 & $16(73)$ & \\
\hline \multirow{2}{*}{ Duration of fever } & $\leq 12$ hours & 67 & 27 & $40(60)$ & \multirow{2}{*}{0.026} \\
\hline & $>12$ hours & 48 & 29 & 19(39) & \\
\hline
\end{tabular}

In brackets: recurrence risk (\%).

\section{Discussion}

In our study majority of the children who were admitted for febrile seizures had simple febrile seizure (81\%). Millichap $\mathrm{JJ}^{6}$ and Mustafic $\mathrm{N}^{7}$ in their study also found higher frequency of simple febrile seizure in their studies. Male sex accounted for higher percentage (62\%) among the study children. Trainor $\mathrm{JL}$ et $\mathrm{al}^{8}$ in their study had shown that $64 \%$ of study population was males. There are other studies $9,10,11$ which had also shown that it is the male children who were predominantly affected.

The most common cause of fever in the study population was viral fever $(60 \%)$ followed by non specific febrile illness and UTI. Millichap JJ et $\mathrm{al}^{6}$. in their study had shown that $35 \%$ of cases had fever of viral origin. Similarly the overall viral identification rate in a study done by Srokes MJ et.al ${ }^{12}$ was $49 \%$. Likewise $53 \%$ of the children had upper respiratory tract infection in a study done by Abuekteish F et.al ${ }^{13}$. In our study we used clinical signs and symptoms to diagnose a child with viral fever. This may be the reason for overestimation of the cases that had viral fever.

In the present study $51 \%$ of children with febrile seizure had recurrence. It is comparable to study done by Pavlidou $\mathrm{E}$ et al who had showed the recurrence rate of $48 \%$ in their study 4 . In our study we found no relation of febrile seizure recurrence with age. Unlike this, other studies ${ }^{4,14,15,16}$ done by different authors have shown that younger age children are prone for the risk of recurrence. This could be because seizure threshold decrease with decreasing age $\mathrm{e}^{14}$.

Several literatures have mentioned that family history of febrile seizure is a risk factor for recurrent febrile seizure ${ }^{10,11}$. In contrast, in our study we found no significant association of febrile seizure recurrence with family history of febrile seizure. This result in our study might have been influenced by a small sample size. In our study we found that those children who had modest rise in temperature (fever $<100^{\circ} \mathrm{F}$ ) on presentation were more likely to have recurrent seizure $(p<0.001)$. There are several literatures to support this finding $4,15,17$. The study by Tarkka $\mathrm{R}$ et.al. has shown no association of recurrent febrile seizure with low grade fever ${ }^{18}$. This finding might be because those children who had recurrent febrile seizure had had the onset of at modest temperatures because they had low threshold for seizure.

This study also has shown that children were more likely to have recurrence of febrile seizure if they had a shorter duration of fever before onset of seizure $(p=0.026)$. Other studies ${ }^{4}$ have also shown similar findings. In addition, this study has shown an increased risk of recurrence of febrile seizure among those who had an atypical presentation. Study by Al-Eissa YA $^{16}$ also reported a similar finding.

This study does not show significant relationship between recurrent febrile seizure and family history of seizure disorder or epilepsy. However there are several studies which showed a direct correlation of recurrent febrile seizure with family history of seizure disorder $r^{18,19,20}$. In this study there was only one case having had a history of birth asphyxia and two cases of psychomotor retardation. Knudsen ${ }^{21}$ also reported no increased risk of recurrent febrile seizure with slight psychomotor delay. Zhao $\mathrm{F}^{11}$ et.al. also reported that birth asphyxia is not a risk factor for recurrent febrile seizure. 


\section{Conclusion}

Febrile seizure is one of the common causes of paediatric hospital admissions. It is common among male children and simple febrile seizure accounts for the majority of the cases. Those children who only had a modest rise in body temperature at the onset of febrile seizure, those who had atypical FS and those children who had an onset of febrile seizure within 12 hours of fever are at high risk of recurrent FS on later date. These findings need further validation with further studies involving large sample size.

Acknowledgement: We thank all the hospital staff for the cooperation given during the study period. We are very thankful to Professor DS Manandhar and Professor MR Baral who encouraged me to carry out this study. I am also thankful to Chandani Thapaliya who helped me during the study period.

Funding: None

Conflict of Interest: None

Permission from IRB: Yes

\section{References}

1. Hitrz DG, Nelson KB. The natural history of febrile seizures. Annu Rev Med 1983;34:453-71.

2. Ostergaard JR. Febrile seizures: Acta Paediatr 2009;98(5):771-3.

3. Pratibha D. Singhi, M. Srinivas. Febrile seizures. Indian Paediatrics 2001;38:733-40.

4. Pavlidou E, Tzitiridou M, Kontopoulos E, Panteliadis CP. Which factors determine febrile seizure recurrence? A prospective study. Brain and Development 2008;30:7-13.

5. Ojha AR, Aryal UR. Leucocytosis in Febrile Seizure. $J$ Nepal Paediatr Soc 2011;31(3):188-91

6. Millichap JJ, Millichap JG. Method of investigation and management of infections causing febrile seizures. Paediatr Neurol 2008;39(6):381-6.

7. Mustafic N, Tahirovic H, Trnovcevic J, Kapidzic A. Clinical characteristics at onset of first febrile convulsions. Acta Med Croatia 2008;62(5):511-5.

8. Trainor JL, Hampers LC, Krug SE, Listernick R. Children with first time simple febrile seizures are at low risk of serious bacterial illness. Acad Emerg Med 2001;8(8):781-7.

9. Bessisso MS, Elsaid MF, Almula NA, Kadomi NK, Zeidan SH, Azzam SB, et al. Recurrent risk after a first febrile convulsion. Saudi Med Journal 2001;22(3):254-8.

10. Pavlidou E, Tzitiridou M, Kontopoulos E, Panteliadis CP. Which factors determine febrile seizure recurrence? A prospective study. Brain and Development 2008; 30:7-13.

11. Zhao F, Emoto SE, Lavine L, Nelson KB, Wang CC, Li SC, et al. Risk factors for febrile seizures in the People's Republic of China: a case control study. Epilepsia 1991;32(4): 510-4.

12. Stokes MJ, Downham MA, and Webb JK, MCquillin J, Gardner PS. Viruses and febrile convulsion. Arch Dis Child 1977;52(2):129-33.

13. Abuekteish F, Daoud AS, al-Sheyyab M, Nouman M. Demographic characteristics and and risk factors for first febrile seizures: a Jordanian experience. Trop Doc 2000;30(1):25-7.

14. Van Stuijvenberg $M$, Steyerberg EW, DerksenLubsen G, Moll HA. Temperature, age and recurrence of febrile seizure. Arch Pediatr Adolesc Med 1998; 152:1170-5.

15. Berg AT, ShlomoShinnar, Amy S. Darefsky, Theodore R. Holford, Eugene D. Shapiro, Morton E. Salomon, Ellen F. Crain, Allen W. Hauser. Predictors of recurrent febrile seizures. Arch Pediatr Adolesc Med 1997; 151(4): 371-8.

16. Al-Eissa YA. Rate and risk factors for recurrence. J Child Neurol 1995;10(4):315-9.

17. El-Radhi AS, Withana K, Banajeh S. Recurrence rate of febrile convulsion related to the degree of pyrexia during the first attack. Clin Pediatr (Phila) 1986;25(6):311-3.

18. Tarkka R, Rantala H, Uhari M, Pokka T. Risk of recurrence and outcome after first febrile seizure. Pediatr Neurol 1998;18(3):218-20.

19. Offringa M, Derksen-Lubsen G, Bossuyt PM, Lubsen J. Seizure recurrence after a first febrile seizure: a multivariate approach. Dev Med Child Neurol 1992; 34(1):15-24.

20. Chung B, Wat LC, Wong V. Febrile seizures in southern Chinese children: incidence and recurrence. Pedatr Neurol 2006; 4(2):121-6.

21. Knudsen FU.Recurrence risk after first febrile seizure and effect of short term diazepam prophylaxis. Arch Dis Child 1985;60(11):1045-9.

\section{How to cite this article?}

Ojha AR, Shakya KN, Aryal UR. Recurrence Risk of Febrile Seizures in Children. J Nepal Paediatr Soc 2012;32(1):33-36. 